\title{
Multiple Local Synaptic Modifications at Specific Sensorimotor Connections after Learning Are Associated with Behavioral Adaptations That Are Components of a Global Response Change
}

\author{
Shlomit Tam, ${ }^{1 \star}$ Itay Hurwitz, ${ }^{1 \star}{ }^{\oplus}$ Hillel J. Chiel, ${ }^{2}$ and ${ }^{\circledR}$ Abraham J. Susswein ${ }^{1}$ \\ ${ }^{1}$ The Mina and Everard Goodman Faculty of Life Sciences and The Leslie and Susan Gonda (Goldschmied) Multidisciplinary Brain Research Center, \\ Bar Ilan University, Ramat Gan 52900, Israel, and ${ }^{2}$ Departments of Biology, Neurosciences and Biomedical Engineering, Case Western Reserve \\ University, Cleveland, Ohio 44106-7080
}

Learning causes local changes in synaptic connectivity and coordinated, global changes affecting many aspects of behavior. How do local synaptic changes produce global behavioral changes? In the hermaphroditic mollusc Aplysia, after learning that food is inedible, memory is expressed as bias to reject a food and to reduce responses to that food. We now show that memory is also expressed as an increased bias to reject even a nonfood object. The increased bias to rejection is partially explained by changes in synaptic connections from primary mechanoafferents to five follower neurons with well defined roles in producing different feeding behaviors. Previously, these mechanoafferents had been shown to play a role in memory consolidation. Connectivity changes differed for each follower neuron: the probability that cells were connected changed; excitation changed to inhibition and vice versa; and connection amplitude changed. Thus, multiple neural changes at different sites underlie specific aspects of a coordinated behavioral change. Changes in the connectivity between mechanoafferents and their followers cannot account for all of the behavioral changes expressed after learning, indicating that additional synaptic sites are also changed. Access to the circuit controlling feeding can help determine the logic and cellular mechanisms by which multiple local synaptic changes produce an integrated, global change in behavior.

Key words: Aplysia; feeding; mechanoafferents; memory; rewiring

\section{Significance Statement}

How do local changes in synapses affect global behavior? Studies on invertebrate preparations usually examine synaptic changes at specific neural sites, producing a specific behavioral change. However, memory may be expressed by multiple behavioral changes. We report that a change in behavior after learning in Aplysia is accomplished, in part, by regulating connections between mechanoafferents and their synaptic followers. For some followers, the connection probabilities change; for others, the connection signs are reversed; in others, the connection strength is modified. Thus, learning produces changes in connectivity at multiple sites, via multiple synaptic mechanisms that are consistent with the observed behavioral change.

Received Nov. 7, 2019; revised Feb. 24, 2020; accepted Feb. 25, 2020.

Author contributions: I.H. and A.J.S. designed research; S.T. and I.H. performed research; S.T. and A.J.S. analyzed data; H.J.C. and A.J.S. wrote the paper.

*S.T. and I.H. contributed equally to this work.

The authors declare no competing financial interests.

This research was supported by Israel Science Foundation Grants 1379/12 and 2396/18, U.S.-Israel Binational Science Foundation (BSF) Grant 2017624, and National Science Foundation-Division of Integrative Organismal Systems-BSF Grant 1754869. We thank Arina Soklakova for performing the behavioral experiment on rejection of a cannula.

Correspondence should be addressed to Abraham J. Susswein at avy@biu.ac.il.

https://doi.org/10.1523/JNEUROSCI.2647-19.2020

Copyright $\odot 2020$ the authors

\section{Introduction}

Memory is expressed by changes at specific, local synapses, and also by widespread, global changes in behavior. How are changes at local synapses related to global changes in behavior? In invertebrate model systems, neurons and synapses are readily accessible, but studies have usually focused on single neural sites producing a specific behavioral change (Kandel, 2001; Hawkins and Byrne, 2015). However, the sites examined are unlikely to be the only ones affected. Learning may produce changes at many sites (Benjamin et al., 2000), reflecting the finding that even simple stimuli recruit many neurons (Zecević et al., 1989), presumably with many functions. Changes in multiple aspects of behavior after an experience are particularly striking in humans 
and in higher animals, in which, with the appropriate experimental techniques, the different aspects are separable (Cohen and Squire, 1980).

Multiple changes in behavior arise from multiple changes in the functional connectome, the set of neurons active while performing a behavior (Alivisatos et al., 2012). To examine how a connectome is functionally rewired (Bennett et al., 2018) and how local synaptic changes can globally affect behavior when long-term memory is expressed, we used an associative learning paradigm in which Aplysia try but fail to consume food (Susswein et al., 1986). Training is characterized by progressively fewer attempts to swallow food, until animals completely stop responding. Long-term memory is expressed by a number of changes in behavior. First, animals make fewer attempts to bite and swallow the food, because of an increased likelihood to produce active rejection responses in place of biting and swallowing. Second, there is a decrease in the time required to stop responding to the food. Third, the decrease is taste specific (Susswein et al., 1986). A recent study (McManus et al., 2019) indicated that the decreased response time is explained by a postsynaptic decrease in the response of neurons in the cerebral ganglion to the transmitter released by chemoafferents responding to food on the lips. However, this study did not account for the increased bias to reject food. Two findings suggested that the changes in behavior that precede the cessation of responses might be localized to a group of mechanoafferents in the buccal ganglia that innervate the interior of the mouth. First, the mechanoafferents release peptides biasing motor activity to rejection (Vilim et al., 2010). Second, molecular correlates of long-term memory formation after training with inedible food are localized to these mechanoafferents (Levitan et al., 2012). We therefore focused on the possible role of these mechanoafferents in an increased bias to reject.

How could an increase in the likelihood to reject food, rather than to ingest it, be expressed in the nervous system? In general, a number of possible mechanisms for choosing a behavior have been found in the nervous system, ranging from command neuron-like systems, in which one behavior suppresses all others; to reorganizing circuitry, in which changes in input "carve out" different patterns of neural activity; to population encoding, in which a continuous range of different behaviors can be generated (Morton and Chiel, 1994; Kristan, 2008). We found that in animals expressing long-term memory that biases feeding to rejection-like activity, the synaptic output of a subpopulation of the mechanoafferents is modified, so as to bias the response to rejection. The bias is accomplished in different ways to different followers, indicating that even a specific aspect of the overall change in behavior does not occur at a single neural site, by a specific neural mechanism, but rather arises by regulating multiple synapses simultaneously. For some synapses between mechanoafferents and their followers, the connection probability changes; in others, connection sign (excitation or inhibition) is reversed; in still others, connection amplitude is increased or decreased. Thus, even a single aspect of memory is expressed by changes at a variety of neural sites, via both functional rewiring (adding or eliminating connections) and changes in relative amplitude.

\section{Materials and Methods}

Animals

Aplysia californica weighing 50-250 g were purchased from Marinus Scientific, and were stored in $600 \mathrm{~L}$ tanks filled with natural Mediterranean seawater maintained at $17^{\circ} \mathrm{C}$. The animals were fed two to three times weekly with Ulva lactuca gathered from the Mediterranean coasts of Israel or were purchased from Seakura (https:// www.seakura.co.il/en/), and stored frozen until used.

\section{Experimental design and statistical analysis}

Training and testing memory. As in numerous previous studies examining learning that food is inedible in Aplysia (Susswein et al., 1986; Katzoff et al., 2002, 2006; Levitan et al., 2012), 24 h before being trained, animals were transferred to $10 \mathrm{~L}$ experimental aquaria that were maintained at room temperature $\left(23^{\circ} \mathrm{C}\right)$. They were kept two to an aquarium, with the two animals separated by a partition allowing the flow of water. As in previous studies (Susswein et al., 1986), the animals were trained with inedible food, the seaweed Ulva wrapped in plastic net. The food induced biting, leading to food entering the buccal cavity, where it induced attempts to swallow. Netted food cannot be swallowed, and it produces repetitive failed swallows. When the unswallowed food subsequently leaves the buccal cavity, the experimenter continues holding it touching the lips, inducing further bites, entries into the buccal cavity, and failed swallows. As training proceeds, many bites fail to cause entry of food into the mouth. When food does enter the mouth, it stays within for progressively shorter periods, eliciting fewer attempted swallows. Training proceeded until the animals stopped responding to food, which was defined as a lack of entry of food into the mouth for $3 \mathrm{~min}$. Data were included only from animals in which food in the mouth elicited failed attempts to swallow for at least $130 \mathrm{~s}$. Animals displaying less time attempting to swallow are relatively unresponsive to food, and are often not well trained and therefore display poor memory. Previous experience (Levitan et al., 2012) showed that use of a criterion of even $100 \mathrm{~s}$ within the mouth almost always shows long-term memory. We used an even more stringent criterion to increase the likelihood of producing memory. Approximately $80 \%$ of the animals satisfied this criterion. A full training session until animals stopped responding to food requires $10-25 \mathrm{~min}$ of training. Such a training session causes long-term memory measured after $24 \mathrm{~h}$. Animals that stopped responding in $<5$ min were discarded.

To be certain that ganglia from animals that were fully trained and that exhibited long-term memory were examined, $1 \mathrm{~h}$ after training the animals were trained a second time, with a procedure identical to that during the first training. The double training was used to increase the likelihood of obtaining animals displaying memory. The next day, before examining the buccal ganglia, memory was tested by training the animals again. Only animals displaying long-term memory, shown by a decrease in the time to stop responding to the food, with respect to the first training, were retained for further study. Approximately $10 \%$ of the animals did not satisfy this criterion and were not used in the subsequent electrophysiological analysis.

Behavioral tests of rejection. Seven animals were trained as above. One hour after the test of memory, animals were again stimulated with food, and when they opened their mouths, a cannula was inserted into the mouth. The cannula was swallowed, and after entry into the gut, when the cannula was no longer gripped by the radula, the cannula was gently pushed further into the gut. The end of the cannula could be felt through the soft skin of the animal. The cannula was marked every half centimeter, allowing one to measure how much had been swallowed. The time required to fully eject the cannula was measured, allowing us to calculate the rate of rejection in centimeters ejected per minute. An identical procedure was also performed in seven naive, untrained controls.

Electrophysiology. Both animals showing long-term memory and controls (naive, untrained animals) were injected with $25-50 \%$ isotonic $\mathrm{MgCl}_{2}$, dissected, and the buccal ganglia (see https://commons.wikimedia. org/wiki/File:Aplysia_californica_buccal_ganglia.jpg) were removed and pinned to Sylgard on the bottom of a Petri dish, and the caudal surface of the ganglia were desheathed. The S1 neurons are one of two clusters of mechanoafferent neurons that innervate the interior of the buccal mass. While recording from a member of the S1 cluster, one of five identified neurons of known function in producing feeding behavior that are located on the same (caudal) surface of the ganglion was then penetrated, and synaptic connections from the S1 neuron to that other neuron were characterized. Electrodes were pulled with a Sutter Brown-Flaming type model 


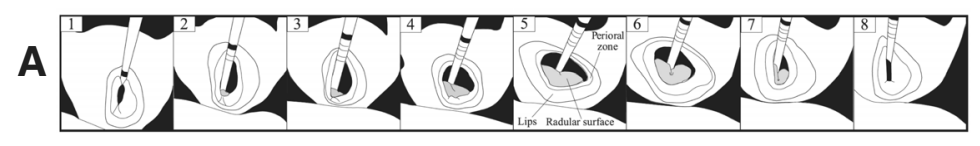

B

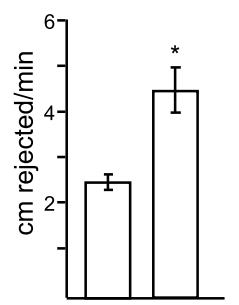

Figure 1. Rejection and modulation of rejection after training. $\boldsymbol{A}$, Rejection of a swallowed cannula. The dark band on the cannula moves away from the jaws in frames 1-8. Note that the tube translates outward. Anatomical features are indicated in frame 5 . The radular surface is labeled, as are the lips and perioral zone (figure is taken from Ye et al., 2006). $\boldsymbol{B}$, Training enhances rejection, as measured by increased rate to reject a swallowed cannula (in $\mathrm{cm} / \mathrm{min})$. Means and SEs are shown $(p=0.002, t=3.97, \mathrm{df}=12$, two-tailed $t$ test; $N=7$ naive animals and $N=7$ trained animals), asterisk marks a significant difference.

97 puller, using $1 \mathrm{~mm}$ thin-walled glass with a filament. The electrodes were filled with $3 \mathrm{~mm}$ potassium acetate and had resistances of 40-60 M $\Omega$. Although this solution is likely to affect the properties of the impaled cells (Hooper et al., 2015), the use of this solution is unlikely to affect results since the same electrodes were used for both naive and trained animals. Recordings were via an Axoclamp 2 voltage clamp/amplifier in currentclamp mode. Noise level was $\sim 200 \mu \mathrm{V}$. For this reason, when analyzing the data, the recorded potential was rounded to the nearest millivolt [i.e., postsynaptic potentials (PSPs) $<500 \mu \mathrm{V}$ were scored as $0 \mu \mathrm{V}$; PSPs $>500 \mu \mathrm{V}$ were scored as $1 \mathrm{mV}$ ]. After documenting the connectivity, a second S1 neuron was penetrated, and connectivity was measured. In many preparations, connections from a number of S1 neurons to a number of followers were sampled. Presynaptic (S1) neurons were stimulated with pulses of depolarizing currents ( $1 \mathrm{nA}, 250 \mathrm{~ms}$ duration, $10 \mathrm{~Hz})$. Each pulse initiated a single action potential. Three trains of five stimuli were delivered $10 \mathrm{~s}$ apart, for a total of 15 pulses. Unless otherwise mentioned, the analyses are of the first PSP recorded in the follower cell. In addition to producing the fast PSP that is the subject of this report, S1 neurons also often produced slow PSPs. These were not analyzed and will be the subject of a future report.

A total of 377 synaptic connections from S1 neurons to the five followers were sampled in $>40$ control preparations, and a total of 371 synaptic connections from S1 neurons to the five followers were recorded in $>40$ preparations from animals that had been trained. The specific number of connections sampled from S1 neurons to each follower is indicated in the legends to the relevant figures.

Statistics. Mann-Whitney $U$ tests were used to compare the overall difference in connectivity between the S1 mechanoafferents and five followers, since the data were not normally distributed. $\chi^{2}$ tests were used to compare the distributions of excitation, inhibition, and lack of a connection, between ganglia from naive and trained animals. Unpaired $t$ tests assuming unequal variance were used to compare differences in amplitude of the first PSP elicited by an action potential in an S1 mechanoafferent between ganglia from trained and untrained animals. When comparing the effects of trains of action potentials on PSPs, a two-way ANOVA was used, which examined the effects of repetition and training. In the behavioral experiment that examined the efficacy of rejections, an unpaired $t$ test assuming equal variance was used.

\section{Results}

\section{Memory is expressed in part by increased rejection of} nonfood objects

Long-term memory after training with inedible food is expressed in part by decreased attempts to bite and swallow the food (Susswein et al., 1986) because of an increased bias to reject the food. The findings that the mechanoafferents produce and release peptides biasing motor activity to rejection (Vilim et al., 2010), and that molecular correlates of long-term memory formation after training with inedible food are localized to these mechanoafferents (Levitan et al., 2012), suggested that long-term memory might also be expressed by an increased tendency to reject even nonfood objects within the mouth. To test this possibility, rejection of a nonfood object placed within the mouth was compared in animals displaying long-term memory after training and in naive controls. As in previous studies, the nonfood object was a cannula that the animals were induced to swallow (Kupfermann, 1974; Morton and Chiel, 1993a; Katzoff et al., 2006; Fig. 1A, rejection process). The length rejected per unit time provided a measure of rejection efficacy. Trained animals displayed significantly improved rejection, as shown by a significantly increased rate of cannula rejection (Fig. 1B), indicating that memory is also partially expressed as an increased bias to reject nonfood objects. We therefore examined neural correlates of increased rejection.

To examine neural correlates of rejection, one must first characterize how rejection differs from other consummatory feeding behaviors controlled by the buccal ganglia. Three different behaviors, biting, swallowing, and rejection, all consist of sequential protraction and retraction of the toothed radula (Kupfermann, 1974). In biting and swallowing, retraction is the power phase, with the two halves of the radula closing on food during retraction, pulling food inward. Protraction is stronger and retraction is weaker in biting than in swallowing (Morton and Chiel, 1993a; Ye et al., 2006; Neustadter et al., 2007; Lu et al., 2015). In contrast, during rejection, protraction is the power phase, with the radula halves closing during protraction, pushing objects out (for examples of biting and rejection, see https:// www.youtube.com/watch? $=y 2 R C c 99 V n Y Q)$. An increased bias to rejection would arise by strengthening synaptic connections biasing toward protraction, while weakening connections biasing toward retraction and biasing radula closing against occurring during retraction.

\section{Synaptic connectivity in naive animals}

To determine whether changes in synaptic outputs of mechanoafferents contribute to increased rejection after training, we first examined in naive animals the monosynaptic connectivity of a subpopulation of mechanoafferents, the S1 neurons, to five followers with different functions (Fig. 2). In these experiments, in each preparation, connectivity of a number of $\mathrm{S} 1$ neurons to the different followers was examined. Only the response to the first spike elicited in the S1 neurons to the five followers was measured.

Surprisingly, the patterns of connectivity of the S1 mechanoafferents differed from those observed in other populations of mechanoafferents, which generally have relatively uniform outputs to their followers (Byrne et al., 1974; Rosen et al., 1979; Walters et al., 1983a). Two followers received exclusively excitatory connections from all S1 neurons that were tested, whereas the other three were excited by some S1 neurons and inhibited by others. The number of unconnected S1 neurons also differed widely among the five followers. There were also different ranges of PSP amplitudes in the different followers (Fig. 3). 
Increased bias to rejection is expressed by changes in synaptic output

To test whether changes in synaptic connections contributed to increased rejection, monosynaptic connections from S1 neurons to the five followers were compared in animals expressing long-term memory and in naive animals. Trained animals showed net increases in excitation to B4/B5 and to B61/B62, and a net increase in inhibition to $\mathrm{B} 3$, with no net changes in connectivity to $\mathrm{B} 8 \mathrm{a} / \mathrm{b}$ and to B31/B32 (Fig. 4).

Synaptic changes are consistent with an increased rejection bias. B4/B5 biases motor patterns toward rejection-like activity (Morton and Chiel, 1993b; Jing and Weiss, 2002; Ye et al., 2006), and the increased excitation to B4/B5 after training (Fig. 4B) would increase the likelihood of this bias. Increased inhibition of B3 after training (Fig. 4C) is consistent with a decreased bias to ingestion, and an increased bias to rejection. This is because B3 (Fig. 2) is a motor neuron exciting muscles active during retraction (Lu et al., 2015), the power phase during ingestion. B4/B5 inhibit B3 at the start of retraction during ingestion to delay its activity. If not for the delay, the lumen of the jaws would close on the grasper too early (Ye et al., 2006). Increased net excitation of B61/B62 after training (Fig. 4D) is consistent with increased rejection, since B61/B62 innervate a muscle (I2) that produces protraction (Hurwitz et al., 1996; Fig. 2), the power phase of rejection. The lack of net change in $\mathrm{B} 8 \mathrm{a} / \mathrm{B} 8 \mathrm{~b}$ (Fig. $4 E$ ) probably reflects their role in activating radula closer muscles (Fig. 2), whose timing may be controlled separately in rejection and ingestion (Morton and Chiel, 1993b; Jing and Weiss, 2002). In rejection, the radula closes during protraction, pushing objects out (Morton and Chiel, 1993b; Jing and Weiss, 2002).

Neurons B31/B32 have a key role in initiating all consummatory behaviors (Hurwitz et al., 2008) (Fig. 2), and are active preceding and during protraction of biting, swallowing, and rejection (Hurwitz et al., 1996). Since memory is expressed in part by a decrease in response to food, one might expect a decrease in excitation to B31/B32. The lack of changes to B31/B32 connectivity (Fig. 4F) suggests that the decrease in the initiation of feeding responses after training may be effected by upstream neurons that respond to food and excite B31/B32 (Hurwitz et al., 2003), rather than by changes in connectivity to B4/B5.

\section{Changes in connectivity arise by changes in the number of excitatory and inhibitory connections, and in their amplitude}

Since individual S1 afferent outputs may not be connected to all follower neurons, or may be either excitatory or inhibitory, increased rejection.
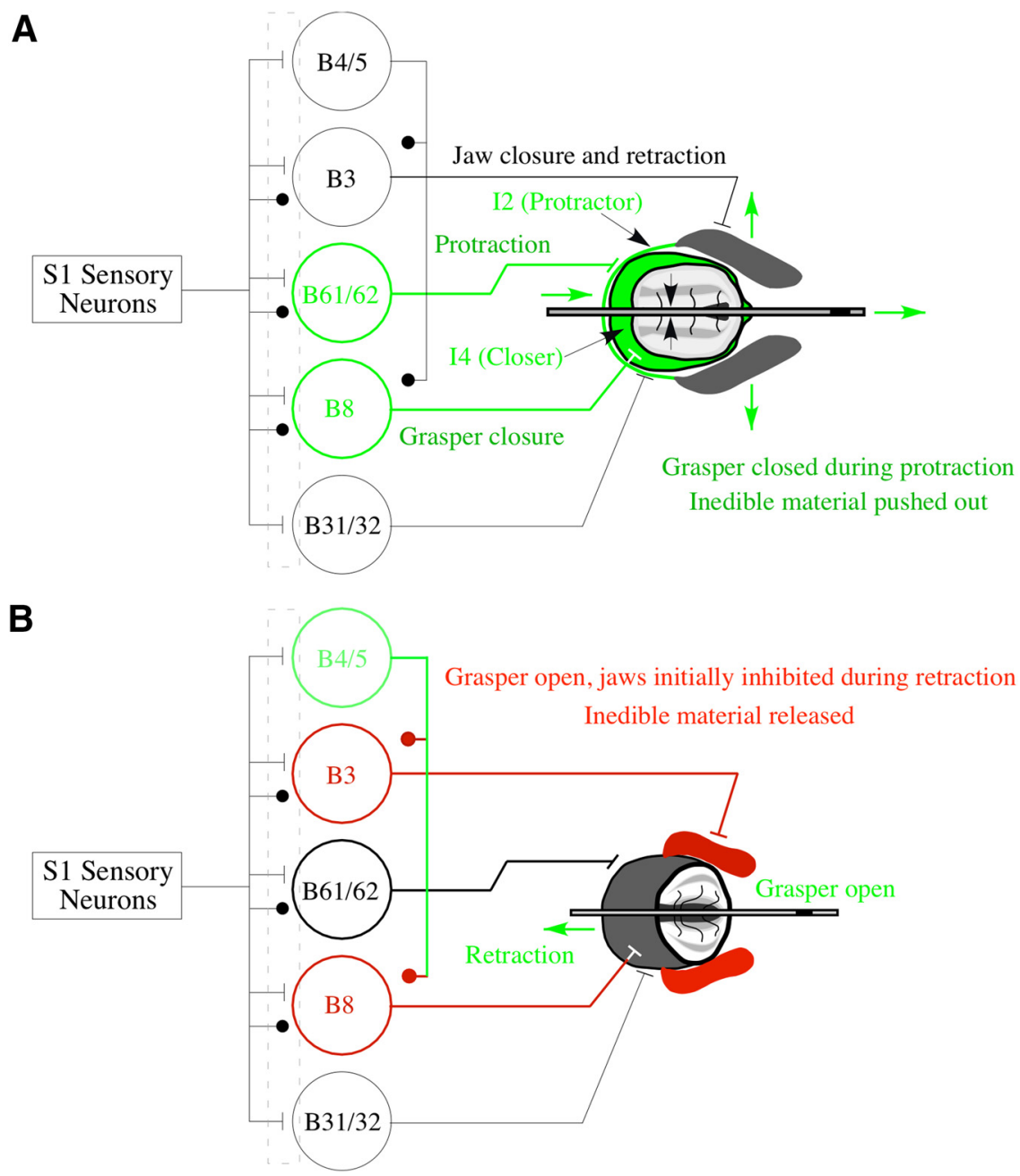

Figure 2. Monosynaptic connectivity of afferents to the five followers examined, and the behavioral functions of the followers. Excitation is indicated by a line, inhibition by a filled circle. $\boldsymbol{A}$, During the protraction phase of rejection, the grasper (closed by the 14 muscle, highlighted in green) is tightly closed on the inedible material (shown schematically as a tube with a mark on it), and is protracted to push the material out of the buccal cavity using the protractor muscle (the 12 muscle, highlighted in green), pushing the anterior jaw muscles open (movements of the tube, grasper, and jaw muscles are indicated ghted in green; Hurwitz et al., 1996). $\boldsymbol{B}$, At the onset of retraction, the B4/B5 multiaction neuron is strongly activated (indicated in green; Ye et al., 2006), inhibiting both the grasper closer motor neuron B8 (shown in red) and the jaw closer motor neuron B3 (shown in red; Lu et al., 2015). As a consequence, the open grasper can move backward through the red) without their closing down on the grasper, which would otherwise cause it to close on the inedible material and pull it back into the buccal cavity (Ye et al., 2006). B31/B32 innervate the I2 muscle (Hurwitz et al., 1994, 1999), but Enhancements of $B 4 / B 5$ activity, of B61/B62 firing, and weakening of $B 3$ firing during retraction would bias behavior toward

changes in the connectivity of the population of mechanoafferents to their followers could result from changes in the number of connections to followers, from the relative proportion of excitation or inhibition, or from changes in the amplitude of excitatory or inhibitory connections. We tested these possibilities.

Training had a differential effect on the distribution of excitatory and inhibitory connections. In ganglia from naive animals, all connections to B4/B5 (Fig. 5A) and B31/B32 (Fig. 5E) were excitatory, with some mechanoafferents not connecting to B4/B5 or B31/B32. Training induced no significant changes in the percentage of $\mathrm{S} 1$ neurons producing monosynaptic excitation onto B4/B5 or B31/B32. In contrast, for B3 (Fig. 5B), B61/B62 (Fig. $5 C$ ), and $\mathrm{B} 8 \mathrm{a} / \mathrm{B} 8 \mathrm{~b}$ (Fig. $5 \mathrm{D}$ ), some $\mathrm{S} 1$ neurons in ganglia from 
B

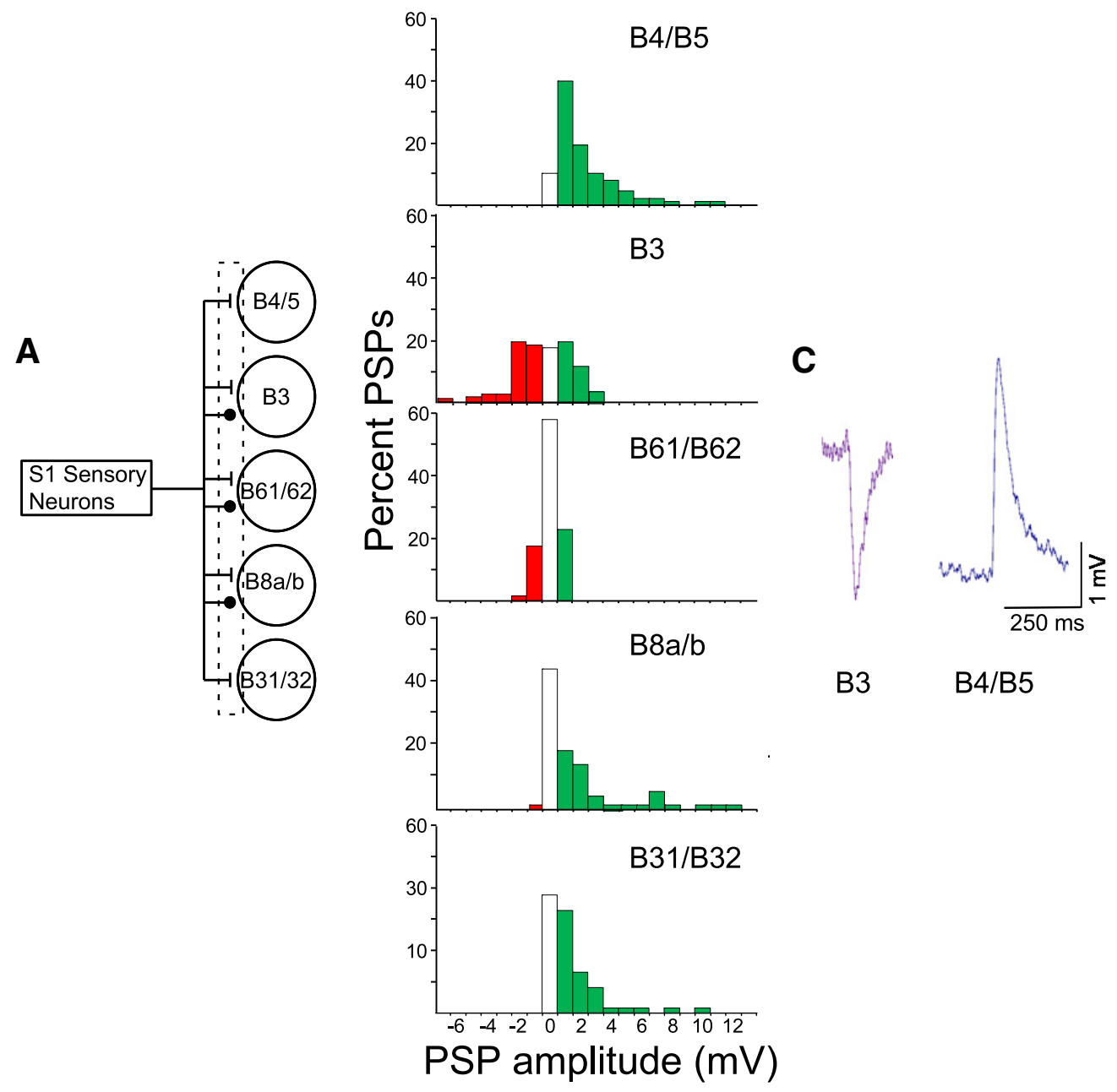

Figure 3. Different patterns of synaptic connectivity from $S 1$ mechanoafferents to five followers. $\boldsymbol{A}$, Connectivity of mechanoafferents to the 5 followers. As above, excitation and inhibition are indicated by a line and a circle, respectively. $\boldsymbol{B}$, Distribution of PSP amplitudes in the five followers of the $S 1$ neurons in naive animals. $0 \mathrm{mV}$ (no connection), shaded white; inhibitory connections, shaded red; excitatory connections, shaded green. Note the differences in distributions of the same population of mechanoafferents to the different follower neurons. $B 4 / B 5$ ( $N=88$ connections measured) and $\mathrm{B} 31 / \mathrm{B} 32$ ( $N=69$ connections measured) do not receive any inhibitory connections. Also note the differences in the percentage of unconnected neurons, and in the different distributions of EPSP and IPSP amplitudes for the five followers ( $N=102$ connections measured to $B 3 ; N=57$ connections measured to $B 61 / B 62 ; N=61$ connections measured to $\mathrm{B} 8 \mathrm{a} / \mathrm{b})$. C, Examples of monosynaptic PSPs to two follower neurons in naive Aplysia.

naive animals produced excitation, others inhibition, and others were unconnected. Training caused significant changes in the distribution of the connections. For B3, inhibitory connections increased; for B61/B62, excitatory connections increased; for $\mathrm{B} 8 \mathrm{a} / \mathrm{B} 8 \mathrm{~b}$, both excitatory and inhibitory connections increased, and unconnected neurons decreased. The increase in inhibitory connections to B3, and the increase in excitatory connections to B61/B62, partially account for the changes in connectivity after training. The increases in both excitation and inhibition to $\mathrm{B} 8 \mathrm{a} /$ $\mathrm{B} 8 \mathrm{~b}$ are consistent with the overall lack of net change after training.

Connection amplitude was also differentially affected by training. The amplitude of the S1 to B4/B5 EPSPs was significantly increased after training (Fig. $6 A, 1$ ), fully accounting for the increased excitation after training. For the connection to B3, the amplitude of excitatory connections was not significantly affected by training (Fig. $6 A, 2$ ), but the amplitude of inhibitory connections was significantly increased (Fig. $6 B, 2$ ). For the connections to $\mathrm{B} 61 / \mathrm{B} 62$, the amplitude of excitatory connections was significantly increased (Fig. 6A, 3). Thus, for the connections to both $\mathrm{B} 3$ and $\mathrm{B} 61 / \mathrm{B} 62$, the net changes in connectivity arise via changes in both the number of connections and in their amplitude. There were no significant changes in the amplitude of the connections in either B8a/B8b or in B31/B32.

\section{Changes in connectivity are retained after multiple spikes}

The analyses above focused on the response of S1 followers to a single spike, but natural stimuli are likely to cause repetitive spiking, which itself could cause plasticity that changes the connectivity both in naive animals and after training. To test this possibility, we delivered three sets of stimuli (five stimuli in each set producing a total of 15 spikes). In addition to examining changes in the net amplitude of the first PSP, changes in the elicited PSP amplitudes were examined for the 5th and 15th stimuli. Two-way ANOVAs determined whether the overall PSP amplitudes were affected by the spike repetitions, by the training history, and by their interaction. Patterns of connectivity were maintained (Fig. 7). Mean PSP amplitude decreased with spike repetition for B4/B5, B61/B62, and B8a/b. Nonetheless, excitation to B4/B4 and to B61/B62 was consistently increased, and inhibition to B3 was consistently decreased after training, 
indicating that the increased bias to rejection after training is maintained.

\section{Discussion}

Explanations of memory in Aplysia and other invertebrates generally focus on neural changes at specific sites, explaining simple behavioral changes (Byrne and Hawkins, 2015). However, in Aplysia learning with inedible food, memory is expressed as a variety of changes in behavior. We have examined neural mechanisms underlying one aspect of memory, an increased bias to rejection. We have found that functional rewiring (i.e., adding or subtracting connections, or changing their sign) and changes in synaptic strength both contribute to changing the functional connectome. Other mechanisms underlie other aspects of the global behavioral change.

We found changes in connectivity between primary mechanoafferents and their followers. Connections from mechanoafferents similar to those examined (Walters et al., 2004) are modified in other Aplysia learning paradigms. The other mechanoafferents were treated as homogeneous populations (Walters et al., 1983b). One might argue that it is inappropriate to explore different memory mechanisms giving rise to multiple changes in behavior by examining primary mechanoafferents. Populations of mechanoafferents in many systems, including in Aplysia, differ in body areas innervated or in activation thresholds, but otherwise have similar outputs (Byrne et al., 1974; Rosen et al., 1979; Walters et al., 1983a). Larger or smaller mechanical stimuli, covering wider or a more restricted areas, recruit more or fewer afferents, thereby producing larger or smaller responses, but responses are qualitatively similar. Surprisingly, the buccal ganglia mechanoafferents produced varied connections to followers with different functions (Fig. 3), combining features of vertebrate dorsal root ganglion mechanoafferents with those of spinal cord interneurons, which receive input from afferents and from higherorder neurons, and distribute inputs to agonists and antagonists to produce an integrated response affecting different muscles (Jankowska, 2001; Butt and Kiehn, 2003). Since S1 mechanoafferents call into play different combinations of motor neurons, their outputs are a good site to change the bias between different behaviors.

The documented connectivity changes are behaviorally appropriate, since they bias the motor system to rejection, by strengthening net excitation to B4/B5 and to B61/B62, and strengthening net inhibition to B3 (Figs. 2, 4). Memory after training with inedible
Net connectivity from $\mathrm{S} 1$

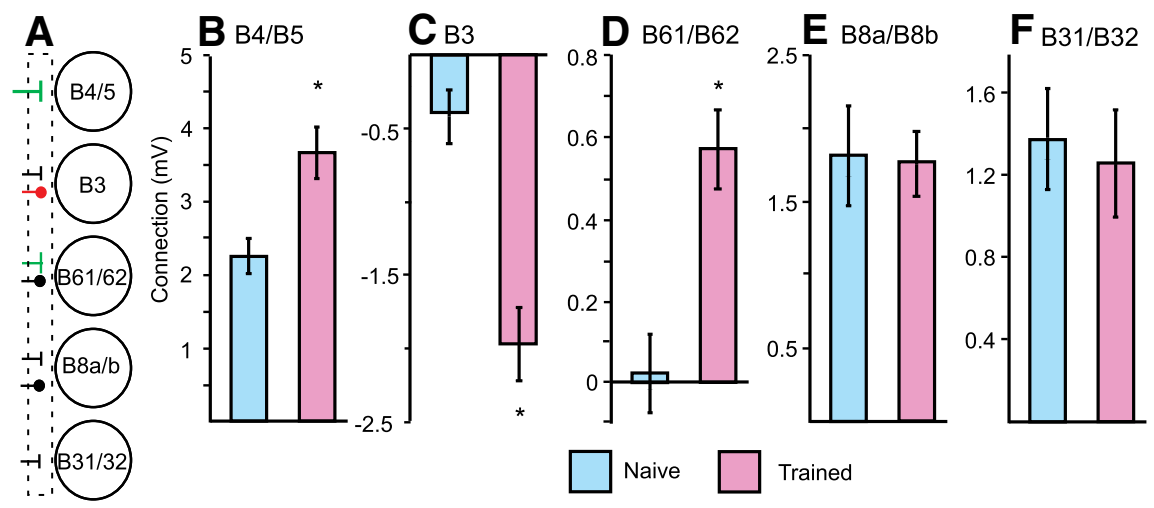

Figure 4. Training biases motor activity toward rejection. $A$, Summary of changes in connectivity after training. As above, excitation and inhibition are indicated by a line and a circle, respectively. Followers with both inhibitory and excitatory connections are shown with both symbols. Increased excitation, green shading; increased inhibition, red shading. $\boldsymbol{B}-\boldsymbol{F}$, Mean net connectivity (average amplitude of all measured connections, both excitatory and inhibitory; unconnected neurons were also included and were given a value of zero) from $\mathrm{S1}$ mechanoafferents to the five followers in ganglia from naive and trained Aplysia. SEs are shown. Significant effects are marked with an asterisk. $B$, Training caused a significant increase (Mann-Whitney $U$ test, $p=0.007)$ in mean excitation of the connections to $B 4 / B 5$ ( $N=88$ connections in naive animals; $N=107$ in trained animals). $C$, Training caused a significant increase (Mann-Whitney $U$ test, $p=0.001)$ in mean inhibition of the connections to $B 3(N=102$ connections in naive animals; $N=104$ in trained animals). $\boldsymbol{D}$, Training caused a significant increase (Mann-Whitney $U$ test, $p=0.001)$ in mean excitation of the connections to $B 61 / B 62(N=57$ connections in naive animals; $N=49$ in trained animals). $\boldsymbol{E}$, Training caused no significant change in mean connectivity to B8a/b ( $N=61$ connections in naive animals; $N=53$ in trained animals) after training (Mann-Whitney $U$ test $p=0.142$ ). $\boldsymbol{F}$, Training caused no significant change in mean connectivity to B31/B32 $(N=69$ connections in naive animals; $N=109$ in trained animals) after training (Mann-Whitney $U$ test $p=0.638)$.

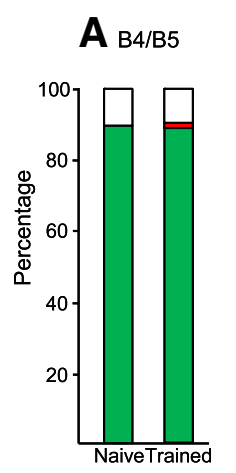

Distribution of synaptic connections from $\mathrm{S1}$
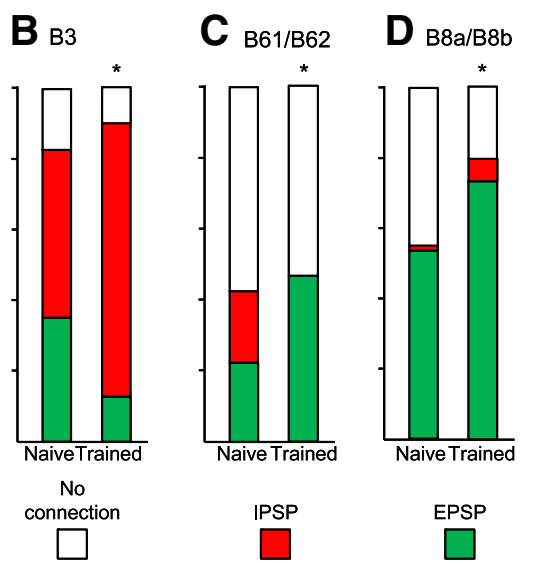

E $_{\text {в31/в32 }}$

Figure 5. Percentage of excitatory, inhibitory, and unconnected S1 mechanoafferents to five followers. The relative changes in excitation, inhibition, or no connection in naive and trained preparations were tested with $\chi^{2}$ tests with 1 or $2 \mathrm{df}$, based on whether naive preparations did or did not have PSPs with net inhibition to a particular follower. Note that the number of connections tested is presented in the previous figure. Significant effects are marked with an asterisk. $\boldsymbol{A}$, Training did not cause a significant difference in the distribution of the type of connections to $B 4\left(p=0.78, \chi^{2}=0.81, \mathrm{df}=1\right)$. Note that, after training, a single inhibitory connection was observed. This did not generate a significant change in connectivity. $\boldsymbol{B}$, Training caused a significant difference in the distribution of the type of connections to $B 3\left(p<0.001, \chi^{2}=35.10, d f=2\right)$, enhancing inhibition. $C$, Training caused a significant difference in the distribution of the type of connections to B61/B62 $\left(p<0.0001, \chi^{2}=22.17\right.$, $\mathrm{df}=2$ ), enhancing excitation. $\boldsymbol{D}$, Training caused a significant difference in the distribution of the type of connections to $\mathrm{B} 8 \mathrm{a} / \mathrm{b}$ $\left(p=0.0001, \chi^{2}=38.14, \mathrm{df}=2\right)$; both the percentage of excitatory and inhibitory connections increased. $\boldsymbol{E}$, Training did not cause a significant difference in the distribution of the connections to $B 31 / B 32\left(p=0.69, \chi^{2}=0.73, d f=1\right)$.

food is expressed in part by fewer attempts to swallow inedible food (Susswein et al., 1986), because of increased bias to rejection. We have now shown that memory is also expressed by an increased bias to reject even nonfood objects(Fig. 1).

Why was net connectivity to some followers not changed by training? Grasper closer motor neurons $\mathrm{B} 8 \mathrm{a} / \mathrm{b}$ are similarly active during ingestion and rejection, although in different phases 


\section{A EPSP amplitude}
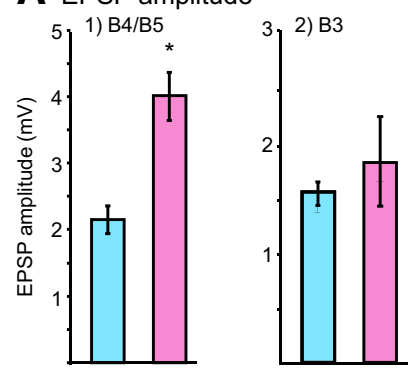

Amplitude of connections from S1

\section{B IPSP amplitude}

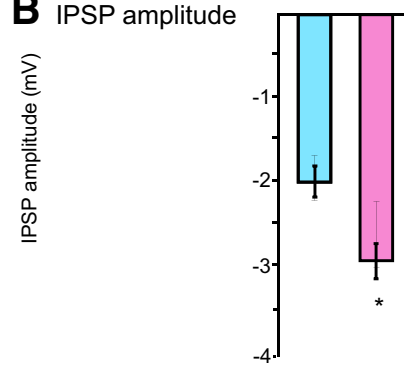

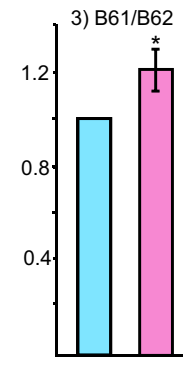
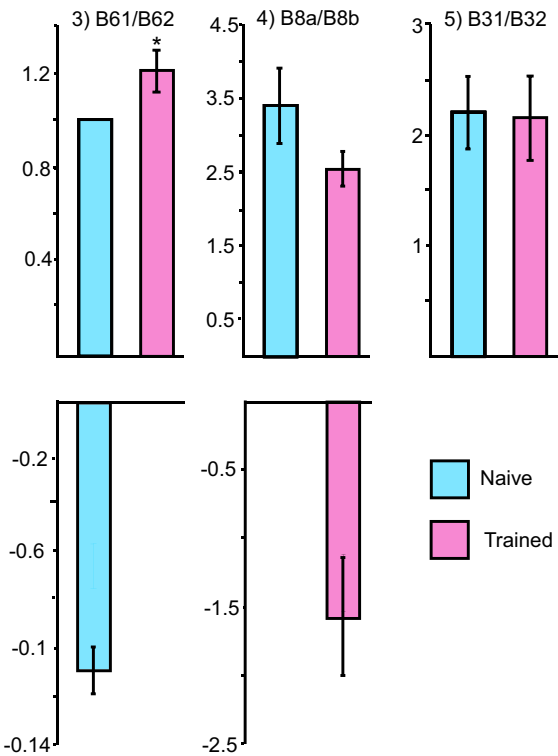

Figure 6. Mean amplitude of excitatory and inhibitory connections from S1 mechanoafferents to 5 followers in ganglia from naive and trained animals. SEs are shown. Significant effects are marked with an asterisk. $A$, EPSP amplitude increased in $\mathrm{B} 4 / \mathrm{B} 5(p=0.003, t=3.64, \mathrm{df}=159.01)$ and in $\mathrm{B} 61 / \mathrm{B} 62(p=0.022, t=2.48, \mathrm{df}=21$; two-tailed $t$ tests assuming unequal variance), but not in the other three followers. All 13 EPSPs to B61/B62 in naive animals were $1 \mathrm{mV}$, and therefore no error bar is shown. $\boldsymbol{B}$, IPSP amplitude increased in B3 $(p=0.0008$, $t=3.45, \mathrm{df}=122.359$; two-tailed $t$ tests assuming unequal variance). Note that there were no IPSPs after training in B61/B62. A single IPSP was seen in B8a/b in naive animals, whose value is not shown. In addition, no IPSPS were present in B4/B5 and in B31/B32 from naive animals, and therefore no changes in IPSP amplitude could have been observed.

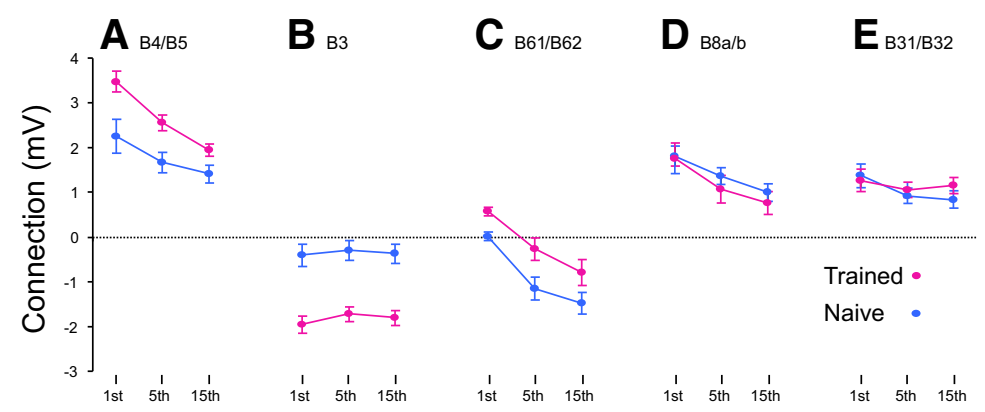

Figure 7. Changes in net connectivity after repeated spikes. All measured connections are shown (the sum of excitatory, inhibitory, and unconnected S1 neurons to each follower cell). A total of 15 stimuli were applied to the presynaptic neurons, in three bursts of five spikes each, separated by $10 \mathrm{~s}$. The data show the net amplitude and SEs of the 1st, 5th, and 15th response. Note that the data for the first PSP are identical to those shown in Figure 2 (blue, naïve; purple, trained). Means and SEs are shown. $A$, Connectivity to B4/B5. A two-way ANOVA showed significant main effects due to training $\left(p<0.001, F_{(1,579)}=31.616\right)$ and due to repetition $(p<0.001$, $\left.F_{(2,579)}=10.981\right)$, with no significant interaction $\left(p=0.546, F_{(2,579)}=0.605\right)$. $B$, Connectivity to B3. A two-way ANOVA showed a significant effect due to training $\left(p<0.001, F_{(1,612)}=78.501\right)$, with no significant effect due to repetition $\left(p=0.694, F_{(2,612)}=0.365\right)$, and no significant interaction $\left(p=0.936, F_{(2,612)}=0.066\right)$. C Connectivity to $B 61 / B 62$. A two-way ANOVA showed a significant increase in the overall connection due to training $\left(p<0.001, F_{(1,312)}=16.115\right)$, as well as a significant effect due to repetition $\left(p<0.578, F_{(2,312)}=21.824\right)$, with no significant interaction $\left(p=0.907, F_{(2,198)}=0.098\right)$. Note that the net connection becomes inhibitory with repeated stimulation, but it is less inhibitory after training. This suggests that other sources of input, not captured in these studies, may account for some of the behavioral changes during the expression of memory. An inhibitory bias for B61/B62 would reduce the likelihood that an animal would respond to food at all, and this is consistent with other behavioral observations after animals are trained on inedible food. Rather than rejecting food, animals simply do not respond to it at all. $\boldsymbol{D}$, Connectivity to B8a/b. A two-way ANOVA showed no significant change in connectivity due to training $\left(p=0.345, F_{(1.528)}=0.894\right)$, but there was a significant decrease in excitation as a result of repetitive spiking $\left(p=0.001, F_{(2,534)}=6.739\right)$, with no significant interaction $\left(p=0.880, F_{(2,534)}=0.127\right)$. $E$, Connectivity to B31/B32. A two-way ANOVA showed no significant change in connectivity due to training $\left(p=0.503, F_{(1,336)}=0.449\right)$, and no significant effect as a result of repetitive spiking $\left(p=0.187, F_{(2,336)}=1.687\right)$, as well as no significant interaction $\left(p=0.585, F_{(2,336)}=0.536\right)$.
(Morton and Chiel, 1993b; Jing and Weiss, 2002), so changes in connectivity to $\mathrm{B} 8 \mathrm{a} / \mathrm{b}$ would not only affect rejection. However, lack of net change in connectivity to $\mathrm{B} 8 \mathrm{a} / \mathrm{b}$ camouflaged increases in the number of both excitatory and inhibitory connections, which cancelled one another (Fig. 5D). The increase in both excitatory and inhibitory connections will lead to an increased conductance, which characterizes $\mathrm{B} 8 \mathrm{a} / \mathrm{b}$ activity during both protraction and retraction phases of ingestion and rejection behavior (Sasaki et al., 2009). The balance between excitation and inhibition causes $\mathrm{B} 8 \mathrm{a} / \mathrm{b}$ to preferentially fire during the phase (Sasaki et al., 2009) when synaptic inputs are most intense. Increased conductance during an active phase of a behavior by increasing both excitation and inhibition is also seen in other repetitive motor behaviors (Berg et al., 2007). Increases after learning of both excitatory and inhibitory inputs may contribute to the increased conductance, allowing only the strongest additional inputs, such as from B4/B5 (Sasaki et al., 2009), to bias responses to rejection.

Lack of change in connectivity to B31/B32 is surprising (Fig. $4 F$ ), since B31/B32 firing initiates all feeding responses (Hurwitz et al., 2008). Since memory is also expressed as a decreased time to stop responding to food (Susswein et al., 1986), one might predict that training would cause decreased excitation to B31/B32, thereby decreasing response likelihood. However, a recent study (McManus et al., 2019) indicated that response cessation after training is localized to cerebral ganglion neurons upstream from B31/B32, which stop responding to acetylcholine released by taste receptors (Xin et al., 1995; Susswein et al., 1996). This change can also account for the taste specificity of memory (Susswein et al., 1986; Schwarz et al., 1988). Thus, the location and mechanism of neural changes accounting for cessation of responses and for taste specificity differ from those biasing feeding toward rejection.

The synaptic changes documented in this study are unlikely to be the only memory mechanisms increasing the bias to reject food. Connections from cerebral ganglion command-like neurons to the buccal ganglia also function in biasing activity to different behaviors (Jing and Weiss, 2001, 2005; Morgan et al., 2002), as do actions of identified buccal ganglia neurons (Teyke et al., 1993; Hurwitz et al., 1997; Nargeot et al., 1999; Jing and Weiss, 2001, 2002; Dacks and Weiss, 2013) not yet examined. In addition, we have not yet analyzed possible changes in connectivity from a second group of buccal ganglia mechanoafferents, the S2 neurons. We have also not yet examined changes in slow PSPs from the S1 and S2 neurons (Levitan et al., 2012) to their followers.

Memory appears to be expressed in some connections as a reversal in the sign of synaptic connections. How is the connection sign reversed? One possibility is that the S1 neurons are heterogeneous, with some neurons producing excitation and others inhibition, and relative strengths of 
excitation and inhibition change, but no sign reversals in fact occur. This possibility is unlikely, since the S1 neurons have exclusively excitatory connections to B4/B5 and B31/B32. Thus, the $\mathrm{S} 1$ neurons are a homogeneous population to these followers, but nonetheless produce mixed synapses onto other followers. Aplysia neurons are known to produce opposite effects on different followers (Kandel et al., 1967), and even opposite effects on a single follower (Wachtel and Kandel, 1967), precluding the need to posit that different populations of S1 neurons underlie excitation and inhibition. In addition, we tested the possibility that outputs of different populations of S1 neurons are differentially modified after training, by dividing the $\mathrm{S} 1$ cells into four subareas. We examined connectivity from each subarea to the five followers, in ganglia from naive and trained animals (S. Tam and I. Hurwitz, unpublished observations). Two-way ANOVAs found no significant interactions between training and location of the S1 neurons for any of the five followers. Thus, the change in the sign of connections is not localized to a specific S1 area.

How could the sign of a connection be reversed? Buccal ganglia mechanoafferents use glutamate and a variety of peptide cotransmitters, with the former producing excitation and the latter inhibition (Brunet et al., 1991; Dale and Kandel, 1993; Walters et al., 2004; Vilim et al., 2010). Since some followers display exclusively excitatory connections, whereas others are either excited or inhibited by different S1 neurons, different terminals might release different transmitter combinations, violating Dale's principle (Eccles et al., 1954). Different terminals of Aplysia bag cells also may release different transmitters (Sossin et al., 1990), as do mammalian motor neurons (Nishimaru et al., 2005). A second possibility is that postsynaptic neurons express different combinations of receptors. Changing the sign of a connection may be achieved by changing the relative distribution of different transmitters released at different terminals, perhaps coupled with changes in postsynaptic receptors to the different transmitters, rather than by de novo growth and retraction of synaptic connections. However, since molecular correlates of learning were previously found only in the mechanoafferent clusters (Levitan et al., 2012) at least some of the changes are likely to be presynaptic.

After training, are changes in connectivity from mechanoafferents to followers a result of inherent synaptic remodeling, or are they a consequence of synaptic changes occurring elsewhere, which secondarily modulate S1 outputs? In conditioning affecting mechanoafferent-to-motoneuron reflexes in mammals, many synaptic changes are seen in the spinal cord, some of which underlie the change in the reflex (Wolpaw, 2010). However, these changes depend on descending signals, indicating that local changes in the spinal cord reflect changes in higher regions, which affect the reflexes (Wolpaw, 2010). In contrast, the changes in connections between S1 neurons and their followers are likely to arise locally. After learning that food is inedible, a molecular correlate of long-term memory formation is localized to the mechanoafferents (Levitan et al., 2012), indicating that these are a primary site for memory formation. It is unlikely that the changes in connectivity also reflect additional primary changes elsewhere within the buccal ganglia (the only ganglia present), since no changes in gene expression in the rest of the buccal ganglia were found after training (Levitan et al., 2012).

The different effects of training on connections from S1 neurons to its followers, biasing behavior to rejection, and the finding that cessation of feeding and taste specificity after training is localized to a different ganglion and occurs via a different cellular mechanism (McManus et al., 2019), indicate that the functional connectome is regulated by learning at a variety of different sites, by different cellular mechanisms. Access to presynaptic and postsynaptic neurons will allow the identification of the signals and the mechanisms producing the individual changes that together lead to a global change in behavior and help clarify the logic of learning at the synaptic level.

\section{References}

Alivisatos AP, Chun M, Church GM, Greenspan RJ, Roukes ML, Yuste R (2012) The brain activity map project and the challenge of functional connectomics. Neuron 74:970-974.

Benjamin PR, Staras K, Kemenes G (2000) A systems approach to the cellular analysis of associative learning in the pond snail Lymnaea. Learn Mem 7:124-131.

Bennett SH, Kirby AJ, Finnerty GT (2018) Rewiring the connectome: evidence and effects. Neurosci Biobehav Rev 88:51-62.

Berg RW, Alaburda A, Hounsgaard J (2007) Balanced inhibition and excitation drive spike activity in spinal half-centers. Science 315:390-393.

Brunet JF, Shapiro E, Foster SA, Kandel ER, Iino Y (1991) Identification of a peptide specific for Aplysia sensory neurons by PCR-based differential screening. Science 252:856-859.

Butt SJ, Kiehn O (2003) Functional identification of interneurons responsible for left-right coordination of hindlimbs in mammals. Neuron 38:953963.

Byrne JH, Hawkins RD (2015) Nonassociative Learning in Invertebrates. Cold Spring Harb Perspect Biol 7:a021675.

Byrne J, Castellucci V, Kandel ER (1974) Receptive fields and response properties of mechanoreceptor neurons innervating siphon skin and mantle shelf in Aplysia. J Neurophysiol 37:1041-1064.

Cohen NJ, Squire LR (1980) Preserved learning and retention of pattern-analyzing skill in amnesia: dissociation of knowing how and knowing that. Science 210:207-210.

Dacks AM, Weiss KR (2013) Release of a single neurotransmitter from an identified interneuron coherently affects motor output on multiple time scales. J Neurophysiol 109:2327-2334.

Dale N, Kandel ER (1993) L-glutamate may be the fast excitatory transmitter of Aplysia sensory neurons. Proc Natl Acad Sci U S A 90:7163-7167.

Eccles JC, Fatt P, Koketsu K (1954) Cholinergic and inhibitory synapses in a pathway from motor-axon collaterals to motoneurones. J Physiol 126:524-562.

Hawkins RD, Byrne JH (2015) Associative learning in invertebrates. Cold Spring Harb Perspect Biol 7:a021709.

Hooper SL, Thuma JB, Guschlbauer C, Schmidt J, Büschges A (2015) Cell dialysis by sharp electrodes can cause nonphysiological changes in neuron properties. J Neurophysiol 114:1255-1271.

Hurwitz I, Goldstein RS, Susswein AJ (1994) Compartmentalization of pattern-initiation and motor functions in the B31 and B32 neurons of the buccal ganglia of Aplysia californica. J Neurophysiol 71:1514-1527.

Hurwitz I, Neustadter D, Morton D, Chiel HJ, Susswein AJ (1996) Activity patterns of the B31/B32 pattern initiators innervating the I2 muscle of the buccal mass during normal feeding movements in Aplysia californica. J Neurophysiol 75:1309-1326.

Hurwitz I, Kupfermann I, Susswein AJ (1997) Different roles of neurons B63 and B34 that are active during the protraction phase of buccal motor programs in Aplysia californica. J Neurophysiol 78:1305-1319.

Hurwitz I, Kupfermann I, Weiss KR (2003) Fast synaptic connections from CBIs to pattern-generating neurons in Aplysia: initiation and modification of motor programs. J Neurophysiol 89:2120-2136.

Hurwitz I, Ophir A, Korngreen A, Koester J, Susswein AJ (2008) Currents contributing to decision-making in neurons B31/B32 of Aplysia. J Neurophysiol 99:814-830.

Jankowska E (2001) Spinal interneuronal systems: identification, multifunctional character and reconfigurations in mammals. J Physiol 533:31-40.

Jing J, Weiss KR (2001) Neural mechanisms of motor program switching in Aplysia. J Neurosci 21:7349-7362.

Jing J, Weiss KR (2002) Interneuronal basis of the generation of related but distinct motor programs in Aplysia: implications for current neuronal models of vertebrate intralimb coordination. J Neurosci 22:6228-6238.

Jing J, Weiss KR (2005) Generation of variants of a motor act in a modular and hierarchical motor network. Curr Biol 15:1712-1721. 
Kandel ER (2001) The molecular biology of memory storage: a dialogue between genes and synapses. Science 294:1030-1038.

Kandel ER, Frazier WT, Coggeshall RE (1967) Opposite synaptic actions mediated by different branches of an identifiable interneuron in Aplysia. Science 155:346-349.

Katzoff A, Ben-Gedalya T, Susswein AJ (2002) Nitric oxide is necessary for multiple memory processes after learning that a food is inedible in Aplysia. J Neurosci 22:9581-9594.

Katzoff A, Ben-Gedalya T, Hurwitz I, Miller N, Susswein YZ, Susswein AJ (2006) Nitric oxide signals that Aplysia have attempted to eat, a necessary component of memory formation after learning that food is inedible. J Neurophysiol 96:1247-1257.

Kristan WB (2008) Neuronal decision-making circuits. Curr Biol 18:R928R932.

Kupfermann I (1974) Feeding behavior in Aplysia: a simple system for the study of motivation. Behav Biol 10:1-26.

Levitan D, Saada-Madar R, Teplinsky A, Susswein AJ (2012) Localization of molecular correlates of memory consolidation to buccal ganglia mechanoafferent neurons after learning that food is inedible in Aplysia. Learn Mem 19:503-512.

Lu H, McManus JM, Cullins MJ, Chiel HJ (2015) Preparing the periphery for a subsequent behavior: motor neuronal activity during biting generates little force but prepares a retractor muscle to generate larger forces during swallowing in Aplysia. J Neurosci 35:5051-5066.

McManus JM, Chiel HJ, Susswein AJ (2019) Successful and unsuccessful attempts to swallow in a reduced Aplysia preparation regulate feeding responses and produce memory at different neural sites. Learn Mem 26:151-165.

Morgan PT, Jing J, Vilim FS, Weiss KR (2002) Interneuronal and peptidergic control of motor pattern switching in Aplysia. J Neurophysiol 87:49-61.

Morton DW, Chiel HJ (1993a) In vivo buccal nerve activity that distinguishes ingestion from rejection can be used to predict behavioral transitions in Aplysia. J Comp Physiol A Neuroethol Sens Neural Behav Physiol 172:17-32.

Morton DW, Chiel HJ (1993b) The timing of activity in motor neurons that produce radula movements distinguishes ingestion from rejection in Aplysia. J Comp Physiol A Neuroethol Sens Neural Behav Physiol 173:519-536.

Morton DW, Chiel HJ (1994) Neural architectures for adaptive behavior. Trends Neurosci 17:413-420.

Nargeot R, Baxter DA, Byrne JH (1999) In vitro analog of operant conditioning in Aplysia. II. Modifications of the functional dynamics of an identified neuron contribute to motor pattern selection. J Neurosci 19:22612272.

Neustadter DM, Herman RL, Drushel RF, Chestek DW, Chiel HJ (2007) The kinematics of multifunctionality: comparisons of biting and swallowing in Aplysia californica. J Exp Biol 210:238-260.

Nishimaru H, Restrepo CE, Ryge J, Yanagawa Y, Kiehn O (2005) Mammalian motor neurons corelease glutamate and acetylcholine at central synapses. Proc Natl Acad Sci U S A 102:5245-5249.
Rosen SC, Weiss KR, Kupfermann I (1979) Response properties and synaptic connections of mechanoafferent neurons in cerebral ganglion of Aplysia. J Neurophysiol 42:954-974.

Sasaki K, Brezina V, Weiss KR, Jing J (2009) Distinct inhibitory neurons exert temporally specific control over activity of a motoneuron receiving concurrent excitation and inhibition. J Neurosci 29:11732-11744.

Schwarz M, Markovich S, Susswein AJ (1988) Parametric features of inhibition of feeding in Aplysia by associative learning, satiation and sustained lip stimulation. Behav Neurosci 102:124-133.

Sossin WS, Sweet-Cordero A, Scheller RA (1990) Dale's hypothesis revisited: different neuropeptides derived from a common prohormone are targeted to different processes. Proc Natl Acad Sci U S A 87:4845-4848.

Susswein AJ, Schwarz M, Feldman E (1986) Learned changes of feeding behavior in Aplysia in response to edible and inedible foods. J Neurosci 6:1513-1527.

Susswein AJ, Rosen SC, Gapon S, Kupfermann I (1996) Characterization of buccal motor programs elicited by a cholinergic agonist applied to the cerebral ganglion of Aplysia californica. J Comp Physiol A Neuroethol Sens Neural Behav Physiol 179:509-524.

Teyke T, Rosen SC, Weiss KR, Kupfermann I (1993) Dopaminergic neuron B20 generates rhythmic neuronal activity in the feeding motor circuitry of Aplysia. Brain Res 630:226-237.

Vilim FS, Sasaki K, Rybak J, Alexeeva V, Cropper EC, Jing J, Orekhova IV, Brezina V, Price D, Romanova EV, Rubakhin SS, Hatcher N, Sweedler JV, Weiss KR (2010) Distinct mechanisms produce functionally complementary actions of neuropeptides that are structurally related but derived from different precursors. J Neurosci 30:131-147.

Wachtel H, Kandel ER (1967) A direct synaptic connection mediating both excitation and inhibition. Science 158:1206-1208.

Walters ET, Byrne JH, Carew TJ, Kandel ER (1983a) Mechanoafferent neurons innervating tail of Aplysia. I. Response properties and synaptic connections. J Neurophysiol 50:1522-1542.

Walters ET, Byrne JH, Carew TJ, Kandel ER (1983b) Mechanoafferent neurons innervating tail of Aplysia. II. Modulation by sensitizing stimulation. J Neurophysiol 50:1543-1559.

Walters ET, Bodnarova M, Billy AJ, Dulin MF, Díaz-Ríos M, Miller MW, Moroz LL (2004) Somatotopic organization and functional properties of mechanosensory neurons expressing sensorin-A mRNA in Aplysia californica. J Comp Neurol 471:219-240.

Wolpaw JR (2010) What can the spinal cord teach us about learning and memory? Neuroscientist 16:532-549.

Xin Y, Weiss KR, Kupfermann I (1995) Distribution in the central nervous system of Aplysia of afferent fibers arising from cell bodies located in the periphery. J Comp Neurol 359:27-643.

Ye H, Morton DW, Chiel HJ (2006) Neuromechanics of multifunctionality during rejection in Aplysia californica. J Neurosci 26:10743-10755.

Zecević D, Wu JY, Cohen LB, London JA, Höpp HP, Falk CX (1989) Hundreds of neurons in the Aplysia abdominal ganglion are active during the gill-withdrawal reflex. J Neurosci 9:3681-3689. 